\title{
Patho-immunological mechanisms of vitiligo: an integration of the immunogenetic milieu, with innate and adaptive immunities, as triggered by environmental stress factors
}

\author{
Safa Faraj ${ }^{1}$, E H Kemp ${ }^{2}$, and DAVID GAWKRODGER ${ }^{3}$ \\ ${ }^{1}$ The University of Sheffield \\ ${ }^{2}$ University of Sheffield \\ ${ }^{3}$ UNIV OF SHEFFIELD
}

April 9, 2021

\begin{abstract}
Epidermal melanocyte loss in vitiligo, triggered by stresses ranging from trauma to emo-tional stress, chemical exposure or metabolite imbalance, to the unknown, can stimulate oxidative stress in pigment cells which secrete damage-associated molecular patterns that then initiate innate immune responses. Antigen presentation to melanocytes leads to stim-ulation of autoreactive $\mathrm{T}$ cell responses, with further targeting of pigment cell. Studies show a pathogenic basis for cellular stress, innate immune responses and adaptive immun-ity in vitiligo. Improved understanding of the aetiological mechanisms in vitiligo has already resulted in successful use of the Jak-1 inhibitors in vitiligo. In this review we outline the cur-rent understanding of the pathological mechanisms in vitiligo, and locate loci to which therapeutic attack might be directed.
\end{abstract}

Patho-immunological mechanisms of vitiligo: an integration of the immunogenetic milieu, with innate and adaptive immunities, as triggered by environmental stress factors

S. Faraj, E. H. Kemp, and D. J. Gawkrodger*

Department of Oncology and Metabolism, and

*Department of Infection, Immunology and Cardiovascular Disease,

University of Sheffield,

Sheffield, UK

ORCID: S. Faraj: 0000-0002-5211-6705

E.H. Kemp: 0000-0002-0313-8916

D.J. Gawkrodger: 0000-0002-6863-7011

Email addresses: S. Faraj: safa_hindaleeba@yahoo.com

E. H. Kemp:e.h.kemp@sheffield.ac.uk

D.J. Gawkrodger:djgawkrodger@yahoo.com

Correspondence: Prof. D.J. Gawkrodger

Department of Infection, Immunology and Cardiovascular Disease, University of Sheffield, Beech Hill Road, Sheffield S10 2RX, UK 
email:djgawkrodger@yahoo.com

Acknowledgement: Dr Faraj was sponsored by the Ministry of Education in Libya, and by

the University of Gharyan, Libya.

Statement: The authors identify no conflicts of interest. No funding was received for this paper. Ethics approval was not required.

\section{Summary}

Epidermal melanocyte loss in vitiligo, triggered by stresses ranging from trauma to emotional stress, chemical exposure or metabolite imbalance, to the unknown, can stimulate oxidative stress in pigment cells which secrete damage-associated molecular patterns that then initiate innate immune responses. Antigen presentation to melanocytes leads to stimulation of autoreactive $\mathrm{T}$ cell responses, with further targeting of pigment cell. Studies show a pathogenic basis for cellular stress, innate immune responses and adaptive immunity in vitiligo. Improved understanding of the aetiological mechanisms in vitiligo has already resulted in successful use of the Jak-1 inhibitors in vitiligo. In this review we outline the current understanding of the pathological mechanisms in vitiligo, and locate loci to which therapeutic attack might be directed.

Key words: Antibodies, Autoimmunity, Cytokines, Cytotoxic T Cells, Th1/Th2 Cells

\section{Introduction}

Melanocyte damage and destruction is the underlying pathological event in vitiligo, a skin disease characterised by depigmented patches. Vitiligo has a worldwide prevalence of about one percent, and can be classified into non-segmental, segmental, mixed and unclassifiable/undetermined vitiligo [1,2]. Differentiating subtypes may be important as they might have different aetiologies. Segmental vitiligo often maps to a blaschkoid or dermatomal distribution [3]. Vitiligo can affect any gender, race or geographic region with no significant difference [4].

Although non-life threatening, vitiligo can have a serious psychological impact on sufferers [5]. Vitiligo patients commonly experience feelings of stress, fear of spreading vitiliginous lesions, embarrassment, negative self-image or self-consciousness [6]. Moreover, patients with vitiligo often experience depression, anxiety and discrimination and stigmatisation from others resulting in low self-esteem and social isolation [7].

In some countries such as India, vitiligo is still confused with leprosy and patients are subjected to antagonism, insult and social stigma [8]. Vitiligo can also have a major negative impact on the marital status and sexuality of patients [9-11]. Furthermore, previous reports have demonstrated that vitiligo patients with decreased quality of life at treatment initiation face a lower response rate to a given therapy [12]. Therefore, the development of specific psychological intervention and quality of life measures may affect positively the outcome of vitiligo treatment and enhance the patient's self-esteem and confidence [13].

A variety of factors may trigger vitiligo, including emotional stress, physical trauma and chemical exposure to imbalances in endogenous neural factors, metabolites, cytokines or hormones, which can stimulate autoimmune responses, in individuals with the appropriate genetic susceptibilities that ultimately target melanocytes [2]. The melanocytes in vitiligo are highly vulnerable to damage and apoptosis under the action of triggering factors [14]. The treatment of vitiligo, including topical steroids, calcitonin-inhibitors, phototherapies, and surgical procedure, in the past has frequently failed to achieve satisfactory repigmentation, but recently, the Jak-1 inhibitors have shown promise [15].

\section{Histopathological Features of Vitiligo and Melanocyte Degeneration}

The affected skin in vitiligo demonstrates melanin loss and absence of or reduced numbers of melanocytes in the epidermis [16]. This decrease varies according to the disease stage [13]. Melanocytes as revealed by using an appropriate monoclonal antibody technique or the Fontana Masson (FM) stain, remain present, however, they disappear from affected skin of vitiligo as the disease progress [17]. Immunohistochemical studies of 
vitiligo lesions show the absence of melanocytes from the basal layer, but they may exist in decreased numbers and can demonstrate degenerative changes [18].

Even though it is clear that depigmentation in vitiligo results from melanocyte loss from the skin, it remains unclear whether this occurs through a degenerative or autoimmune process. Defective in vitrogrowth of melanocytes derived from individuals with vitiligo $[19,20]$ and increased susceptibility of vitiligo melanocytes to exogenous stimuli suggests that degeneration may elucidate melanocyte loss [21].

Melanocytes from vitiligo subjects were shown to poorly proliferate compared to healthy normal melanocytes [19] and also they show inadequate antioxidant activity with high levels of superoxide dismutase and low levels of catalase [22]. Under normal circumstances, superoxide dismutase catalyses the first step of dismutation by converting the superoxide anion into oxygen and hydrogen peroxide and then catalase enzyme transforms hydrogen peroxide into water and oxygen, protecting cells from reactive oxygen species (ROS). In fact, melanocytes synthesise high ROS levels as by-product of melanogenesis. Therefore, compensatory media supplements such as growth factors or catalase are required to culture melanocytes derived from vitiligo patients [20, 23]. Also, increased expression of hydrogen peroxide and elevated oxidative by-products within vitiligo patient skin has been reported $[22,24,25]$. In addition, melanocytes from vitiligo patients were more sensitive to in vitro oxidative therapies such as cumene hydroperoxide and UVB light $[26,27]$. However, exogenous treatment of catalase (pseudocatalase), which was proposed to cure vitiligo by regulating ROS, was ineffective in treating vitiligo lesions [28]. Thus, dysregulated redox balance in vitiligo might be a consequence, but not a cause, of vitiligo. Melanocytes from vitiligo patients show morphological and physiological abnormalities. Those in peri-lesional borders are seen to be enlarged with longer dendritic ends than normal melanocytes [29]. However, rapid regimentation of the skin following engrafting of human vitiligo lesional skin on nude mouse was achieved, indicating that intrinsic melanocyte defect was not the only cause of melanocyte destruction in vitiligo [30]. Histochemical and immunohistochemical examination shows infiltration of a large number of $\mathrm{T}$ lymphocytes at the edge of vitiligo lesions with a complete microscopic loss of melanin in lesional skin [31]. Therefore, it is certain that vitiligo melanocytes are abnormal compared to healthy melanocytes, but this abnormality does not seem to be sufficient for the disorder.

\section{Responses to Stress in Vitiligo}

Melanocytes in the epidermis are regularly exposed to various environmental stressors e.g., ultraviolet (UV) radiation, pollution, microorganisms and oxidising chemicals, which can stimulate reactive oxygen species production [32].

Reactive oxygen species consist of a number of oxygen-based free radicals such as superoxide and hydrogen peroxide, formed during multiple physiological and pathological processes [33]. Such free radicals are constantly scavenged by antioxidants such as superoxide dismutase, catalase, vitamin C, and vitamin E. As mentioned above, in vitiligo patients, high levels of superoxide dismutase and low levels of catalase have been observed in their skin [34]. Hydrogen peroxide created from superoxide anion can easily cross melanocyte membranes causing cellular damage [33]. Even though melanin present in the skin protects melanocytes as well as adjacent keratinocytes through its ability to absorb UV radiation, its synthesis likewise results in higher amount of intracellular reactive oxygen species, causing to be melanocytes more vulnerable to oxidative stress $[35,36]$. In addition, a decrease in the stability of tyrosinase-related protein-1 (TYRP1), which is required for melanin synthesis, has been observed in vitiligo melanocytes, allowing accumulation of melanin intermediates [37]. The build-up of intermediate products increases the risk of protein misfolding, hence activating the unfolded protein response. This in turn induces the restoration of endoplasmic reticulum homeostasis through the halting of protein translation, inducing misfolded protein degradation and promoting the synthesis of chaperons to facilitate protein folding, sustained activation of which leads to apoptosis [2].

Intrinsic defects may also render vitiligo melanocytes vulnerable to oxidative stress. Observed anomalies include a dilated endoplasmic reticulum, mitochondrial dysfunction, and an abnormal melanosome structure, all of which suggests that these pigment cells are less capable of dealing with such stressors than those from 
healthy individuals [32]. ROS-mediated stress has been directly linked with generation of neoantigenic epitopes within beta islet cells [38], and likewise melanocyte stress may generate neoantigens. Elevated ROS in melanocytes of vitiligo subjects has been correlated with peroxidation, and thus it is likely that ROS generates melanocyte neoantigens via protein carbonylation and oxidation [39].

Cellular stress has been found to develop in healthy melanocytes exposed to phenolic derivatives such as 4-tertiary butylphenol and monobenzyl ether of hydroquinone[40]. Once melanocytes become stressed, they promote the secretion of inducible heat shock protein 70 (iHSP70), which has been detected in vitiligo melanocytes and seen to correlate with active disease [41]. Pathogens or damage-associated molecular patterns (DAMP), which can evoke inflammation via pattern recognition receptors (PRRs) including Toll-like receptors and nucleotide oligomerization domain (NOD)-like receptors (NLRs). Indeed, NLRP1 has been linked with vitiligo in a linkage study [42]. Innate immunity is activated by the release of DAMPs from stressed cells. DAMPs are likely to be constantly released from stressed melanocytes resulting in skin inflammation in patients with vitiligo [43]. In agreement with this, uninvolved skin of vitiligo patients shows increased numbers of lymphocytes in comparison with healthy controls [44]. In addition, increased iHSP70 expression in the skin of vitiligo patients causes melanocytes loss [45]. Mice lacking expression of iHSP70 will not develop experimental depigmentation, suggesting a role for iHSP70 in vitiligo [46]. iHSP70 has been found to have potent adjuvant and chaperone properties [47]. Under conditions of oxidative stress, genetically compromised melanocytes secrete melanosomal peptides-chaperoned iHSP70 that can activate dendritic cells and release the inflammatory signal that initiates the immune response in vitiligo [46]. Secreted iHSP70 from stressed vitiligo melanocytes was reported to induce dendritic cells to elevate the expression of coactivation markers CD80 and CD86, stimulating immune responses to melanocytes [48, 49]. Therefore, it is likely that melanocyte stress can contribute to instigation of autoimmunity through both neoantigen generation and activation of innate immunity [39]. iHSP70 is thus a link between oxidative stress as a trigger and the onset of the autoimmune reaction in vitiligo.

\section{Innate Immunity}

Innate immunity is based on the ability of PRRs to detect pathogen-associated molecular patterns (PAMPs) found in pathogens or DAMPs released by damaged cells [50]. Reactive oxygen species and iHSP70 produced by stressed melanocytes serve as DAMPs in vitiligo, and PRRs initiate the innate response [43]. Innate immune cells such as natural killer (NK) cells, macrophage and dendritic cells show aberrant activation in vitiligo skin and granzyme-B (GZMB)-expressing activated NK cells have been found [44, 46]. Vitiligo skin shows an increase in NK cells activating receptors (CD16+CD56+ and CD3+CD16+CD56+), an upregulation in CLEC2B, an activating ligand of NK cells, and a decrease in the inhibitory receptors $(\mathrm{CD} 16+\mathrm{CD} 158 \mathrm{a}+)$. Vitiligo skin also demonstrates increased numbers of dendritic cells, which can destroy melanocytes when activated by iHSP70 [46, 51]. While chemicals can trigger vitiligo by inducing melanocyte stress, adding HSP70i alone aggravates vitiligo mouse model, probably via the activation of dendritic cells in the skin [45].

In addition, mutant HSP70i delivery, which interferes with the signaling pathway of endogenous HSP70i, could inhibit depigmentation in vitiligo mouse and swine models by interfering with dendritic cell activation $[46,52]$. Thus, DAMPS, in particular HSP70i, can directly initiate vitiligo in animal models by activating dendritic cells. Activated, dendritic cells locally synthesise cytokines, inducing $\mathrm{T}$ cell activation and recruitment to the skin and, in local lymph nodes, recruit cytotoxic $\mathrm{T}$ cells, thus bridging the innate with the adaptive immunity [53]. Therefore, delivery of mutant HSP70i may offer a potential treatment for vitiligo by altering the innate immunity. The connection in vitiligo between cellular stress and cell-based immunity was illustrated when melanocytes, stressed by exposure to 4-tertiary butyl phenol, were noted to facilitate activation of dendritic cells thus rendering them melanocytotoxic in vitro [48]. Others have demonstrated that stressed melanocytes can activate melanocyte-specific CD8 $+\mathrm{T}$ cells, resulting in an autoimmune response and consequent pigment cell destruction [54]. Recently, perilesional keratinocytes from vitiligo skin, under oxidative stress in vitro, have been shown to exhibit increased expressions of NLR family pyrin domain containing 3 (NLRP3) and downstream cytokine IL-1 $\beta$, an inflammasome regulator that may modulate innate 
immune attack on melanocytes [55].

NLRP3 is a cytoplasmic NLR and is an essential constituent of the inflammasome in the innate immunity. The activation of NLRP3 inflammasome requires two signals. The first signal primes cells and induces NLRP3 expression by nuclear factor $\mathrm{kB}$ (NF-kB)-mediated signaling [56], while the other signal requires mitochondrial reactive oxygen species (mtROS) and interaction of NLRP3 and apoptosis-associated specklike protein containing a CARD (ASC) [57]. In addition, the NLRP3 inflammasome can also be activated through transient receptor potential cation channel subfamily M member 2 (TRPM2)-induced intracellular and mitochondrial calcium influx in $\mathrm{H}_{2} \mathrm{O}_{2}$-treated keratinocytes [55]. Once activated, NLRP3 inflammasome mediates caspase- 1 cleavage which promotes synthesis of IL- $\beta[58,59]$. Subsequently, the function of CD8+ and CD4+ T cell is strengthened through IL1- $\beta / \mathrm{IL}-1 \mathrm{R}$ signaling pathway [55]. IL1- $\beta$ elevated the expression of CXCR6 and CXCR3 in CD8+ T cells from vitiligo patients. Also, IL1- $\beta$ increased the synthesis of IL17A/F in CD4+ T cells and IFN- $\gamma$ in both CD8+ and CD4+ T cells [55]. IL1- $\beta$ in stressed keratinocytes also stimulated the expression of CXCL10 and CXCL16, ligands of CXCR3 and CXCR6 through NF-kB pathway, which promote the migration of cytotoxic T cells into vitiligo lesions [55] (Figure 1 ).

\section{Adaptive Immunity}

\section{Infiltrating $\mathbf{T}$ Cells and their Role in Vitiligo}

Following proinflammatory signalling in the skin, melanocyte antigens can be processed and presented by dendritic cells in the draining lymph node, resulting in the production of melanocyte-specific cytotoxic $\mathrm{T}$ lymphocytes and the generation of melanocyte-specific antibodies by B lymphocytes [60]. Histological studies of vitiligo lesions showed infiltration of lymphocytes at the border of depigmented lesions. These infiltrates consist mainly of CD8 $+\mathrm{T}$ cells, preferentially located in the dermo-epidermal borders neighbouring the melanocytes [61, 62]. CD8+ T cells are implicated in the destruction of melanocytes in vitiligo. Melanocytotoxic CD8+ T cells that express the skin homing marker, cutaneous lymphocyte-association antigen, infiltrate the lesional borders of vitiliginous skin, and their number correlates with disease extension and severity [63-65]. 


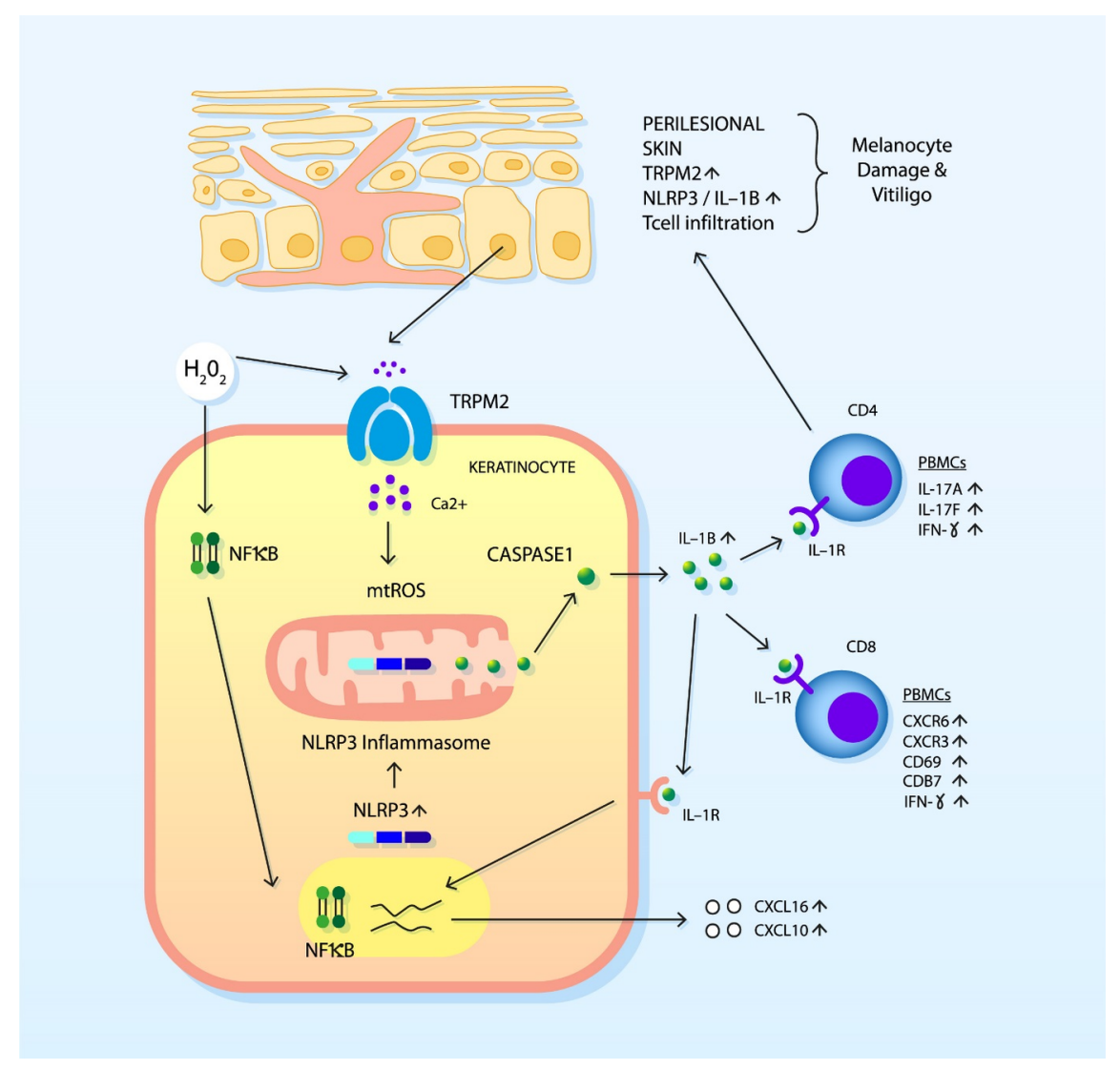

Figure 1. Activated NLRP3 inflammasome in keratinocytes promotes T cell responses in vitiligo. NLRP3 inflammasome in stressed keratinocytes is activated by NF-kB-mediated signaling as well as the interaction between mtROS and of NLRP3. NLRP3 inflammasome can also be activated through TRPM2-mediated intracellular and mitochondrial calcium influx. Once activated, NLRP3 inflammasome mediates caspase-1 cleavage which provoke synthesis of IL- $\beta$, resulting in the activation of D8+ and CD4 $+\mathrm{T}$ cells through IL1- $\beta /$ IL-1R signaling pathway. IL1- $\beta$ augments CXCR6 and CXCR3 expression in CD8+ T cells, IL17A/F synthesis in $\mathrm{CD} 4+\mathrm{T}$ cells and IFN- $\gamma$ production in both CD8+ and CD4+ T cells. IL1- $\beta$ also promotes the expression of CXCL10 and CXCL16. TRPM2-facilitated NLRP3 inflammasome activation in keratinocytes stimulates $\mathrm{T}$-cell function in vitiligo patients as demonstrated by upregulation of $\mathrm{T}$ cell activation markers CD69 and CD137 (Adapted from Li et al., 2020)[55].

Furthermore, perilesional infiltrating self-reactive CD8+ $\mathrm{T}$ cells in vitiligo patients recognise MelanA/MART, tyrosinase (TYR) and melanocyte-specific protein, all of which are antigens involved in the melanogenic pathway [66].

Vitiligo patients showed elevated numbers of CD8+ T cells in their blood compared to healthy individuals [64].

Moreover, peri-lesional skin of vitiligo patients are highly infiltrated by melanocyte-specific CD8+ T cells [62], and these cells have the ability to kill melanocytes in vitro [62, 67, 68]. CD8+ T cells isolated from peri-lesional skin of vitiligo patients infiltrate explants of autologous healthy pigmented vitiligo skin and eliminate melanocytes in a way similar to the clinical pathology of vitiligo [68]. Importantly, isolated CD4+ $\mathrm{T}$ cells were incapable of inducing melanocyte apoptosis in autologous skin explants [68]. In vitro culture of CD8+ and CD4+ T cells derived from peri-lesional vitiligo skin secrete high levels interferon- $\gamma$ (IFN- $\gamma$ ), a pro-inflammatory cytokine required for melanocyte-specific autoreactive CD8+ T cell recruitment [69]. 
These findings provide robust evidence that CD8 $+\mathrm{T}$ cells are equally essential and sufficient for destruction of melanocytes in vitiligo lesions.

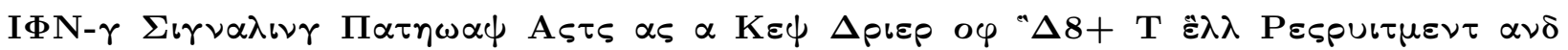

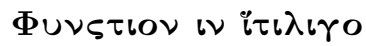

The mechanism by which CD8+ T cells trigger melanocytes apoptosis requires their secretion of proinflammatory cytokines IFN- $\gamma$ from CD8 $+\mathrm{T}$ cells [68]. Analysis of gene expression in human vitiligo lesional skin demonstrated increased expression of $\operatorname{IFRG}$ gene [70,71], as well as genes induced by IFN- $\gamma$ and these include C-X-C chemokine receptor type 3 (CXCR3), a T cell chemokine receptor, and its ligands: CXCL9, CXCL10, and CXCL11 [71]. In agreement with this finding, skin biopsies from vitiligo patient lesions also show prominent lymphocyte infiltrates that are primarily CXCR3+ $69,71-73]$. In addition, melanocytespecific CD8+ T cells isolated from the skin and blood vitiligo subjects predominantly express CXCR3 receptor, and CXCL9 is a specific skin biomarker of active vitiligo [65]. Studies in mouse models of vitiligo established a critical role for pathway in pathogenesis of vitiligo, since INF- $\gamma$, CXCR3, CXCL10 are all essential for vitiligo development $[71,74]$. Neutralization of IFN- $\gamma$ with antibody treatment or the lack of CXCR3 expression on $\mathrm{T}$ cells prevents the migration of autoreactive $\mathrm{T}$ cells into the skin and therefore do not cause depigmentation [71, 74]. Studies employing chemokine reporter mice showed that CXCL9 and CXCL10 are mostly produced by keratinocytes, and functional studies demonstrated that keratinocytes are primarily responsible for recruitment of autoreactive $\mathrm{T}$ cells [75].

CXCL9 seems predominantly responsible for bulk recruitment of $\mathrm{T}$ cells to the skin, since when it is absent the number of melanocyte autoreactive $T$ cells within lesional skin of vitiligo is decreased by tenfold [71]. However, in spite of reduced number of $\mathrm{T}$ cells, vitiligo severity remains unchanged, indicating that the over-recruitment of $\mathrm{T}$ cells occurs during vitiligo. In contrast, when CXCL10 is absent, the incidence and severity of vitiligo are decreased, yet bulk recruitment of $\mathrm{T}$ cells is unchanged [71].

Interestingly, in the absence of CXCL10, the quantity of $\mathrm{T}$ cells shown in the epidermis compared to the dermis in the skin is decreased, signifying that CXCL10 is responsible for T cell localisation within the skin and their effector function [71]. Thus, T cells produces IFN- $\gamma$, which stimulates the production of CXCL9 and CXCL10 from keratinocytes to recruit more T cells and induce vitiligo progression [39]. As well as to vitiligo initiation and progression, the IFN- $\gamma$-chemokine pathway is also needed for maintenance of established vitiligo lesions, as knocking out CXCR3 or blocking CXCL10 action prevents and reverses depigmentation in vitiligo [71] (Figure 2). Indeed, ruxolitinib, a janus kinase (JAK)-1,2 inhibitor, which interferes with IFN- $\gamma$ signalling pathway through preferential inhibition of JAK1 and JAK2, shows promise in vitiligo [76].

\section{Regulatory T Cells are Suppressors of Autoreactive Effectors and Inhibit Depigmentation}

Regulatory T (Treg) cells and effector T cells are key factors in maintaining appropriate peripheral tolerance. Treg cells are a subgroup of CD4 $+\mathrm{T}$ cells that primarily represent a phenotype of CD4+, CD25+ and forkhead box P3 (Foxp3). They have a vital role in controlling autoimmunity by maintaining immunological unresponsiveness to self-antigens, playing a key role in preventing autoimmunity.

Patients who suffer from immuno- dysregulation, polyendocrinopathy, enteropathy, X-linked syndrome lack Treg cells because of a mutation in the FOXP3 gene and as a consequence suffer from other autoimmune diseases, including vitiligo [77]. Likewise, scurfy mutant mouse strain with defective FOXP3 lack Treg cells and shows widespread autoimmunity, underlining a critical role for Treg cells in maintenance of tolerance to self-antigens [78]. 


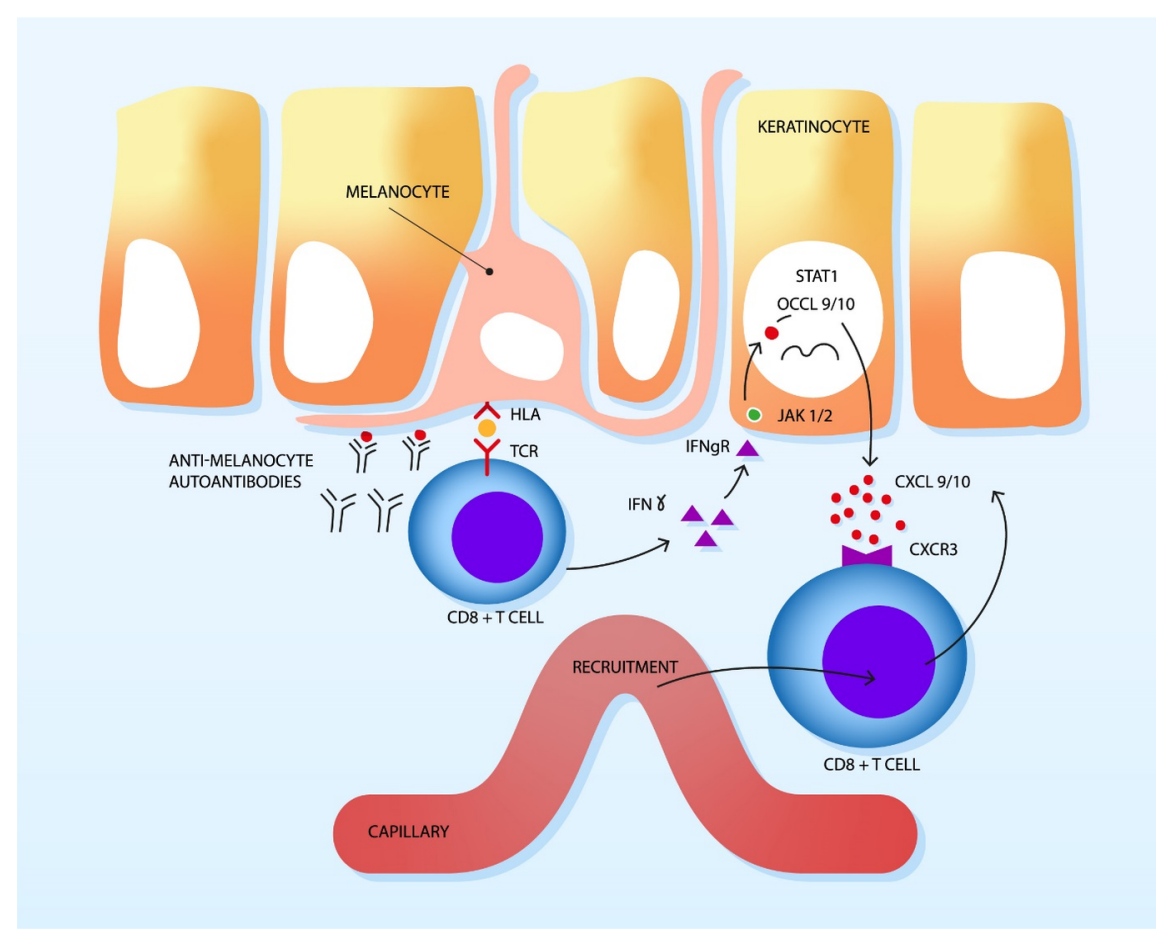

Figure 2. Progression of vitiligo requires continued recruitment of $T$ cells which occurs via a positivefeedback loop. In the progressive phase of vitiligo, melanocyte-reactive $\mathrm{CD} 8+\mathrm{T}$ cells produce interferongamma on encountering melanocyte antigens. These induce keratinocytes to secrete CXCL 9 and CXCL 10, resulting in additional recruitment of lymphocytes to the site through the CXCR3 receptor (Adapted from Frisoli et al., 2020)[39].

In a mouse model of vitiligo, repigmentation was accompanied by an elevated infiltration of Tregs into the skin, possibly resulting in the prevention of immune responses against melanocytes [79]. In addition, studies reported an increase in vitiligo severity when Treg cells were depleted using either CD4 or CD25 antibodies $[80,81]$. One study showed an increase in cutaneous Treg cell infiltration and a decrease in depigmentation when the expression of CCL22 was induced in the skin [82]. Another report revealed that adoptive transfer of exogenous Treg cells vitiligo prone mice at three weeks of age led to elevated number of cutaneous Treg cells and prevented vitiligo [81].

When vitiligo prone mice were injected with PD-L1P-Fc, Treg cell accumulation in the skin was enhanced and depigmentation was reversed [83]. These findings support the theory that the number of Treg cells in skin is critical for reducing depigmentation driven by $\mathrm{T}$ effectors and therefore helping to control vitiligo progression.

Several groups have reported disruption of Treg cells function, but there is no consensus as to where the disruption exactly lies: in density of Treg cells, suppressive effects, or immigration ability to the skin. Studies reported that peripheral Treg cells isolated from vitiligo patients showed a decreased ability to inhibit CD8+ $\mathrm{T}$ cells proliferation and activation in vitro [84]. However, another study showed normal Treg cell activity in vitiligo patients but decreased number in the skin, suggesting that reduced cutaneous localization of Treg cells to the skin, rather than diminished function of Treg cells, contributes to vitiligo pathogenesis [85] . Immunohistochemical studies revealed no significant reduction in Treg cell number in vitiligo lesional skin [86, 87], whereas another report showed a significant decrease in these cells [88]. It is therefore not clear how the function of Treg is disrupted in vitiligo patients, but effector $\mathrm{T}$ cell phenotype in human vitiligo also indicates the presence of defective Treg T cells. Naturally occurring Treg cells reduce self-reactive T cell 
proliferation and activation, a phenomenon called anergy, and analysis of the phenotype of peripheral blood mononuclear cells indicates that melanocyte-autoreactive CD8+ T cells escape anergy in vitiligo patients [89]. Further studies are required to reliably determine how deficiency of Treg cells contributes to the development of vitiligo, and to examine the potential of improving Treg cell function as a novel treatment for vitiligo.

\section{Immune-Dysregulation of T Helper Cells in Vitiligo}

The numbers of circulating Th1 and Th17 cells are increased in vitiligo compared to controls [90]. A mouse model of vitiligo shows a predominantly Th1-mediated pattern with a dominant role of CXCL10 [73]. Serum levels of interleukin 17 (IL-17), the effector molecule of Th17 cells, are raised in vitiligo patients, and IL17 mRNA is elevated in their skin, implying a role for Th17 cells in driving the inflammatory response [91]. Recently, decreased frequencies of circulating Th1/Tc1, Th17/Tc17 and Th1/Th17-Tc1/Tc17 cells were shown in patients with vitiligo, suggesting possible migration of these cells into the skin [92]. Indeed, Th1/Th17, Tc1/Tc17 and Th17 cells have been touted as potential targets for therapy [93].

\section{Resident Memory T Cells and their Function in Vitiligo}

The risk of repigmentation relapse in vitiligo lesions is common and occurs within the first year following treatment cessation [94]. To date, there is no treatment to prevent relapses. One study showed that vitiligo patients treated with narrow band-ultraviolet B (NB-UVB) lost their new pigment two years after cessation of treatment [95]. Notably, relapse occurs in exactly the same previously repigmented lesions, suggesting that autoimmune memory plays a role in the skin that is not cleared by current treatments [39]. Resident memory $\mathrm{T}(\mathrm{Trm})$ cells are a subset of long-lived $\mathrm{T}$ cells that persist within most nonlymphoid tissues after inflammation or infection driven by $\mathrm{T}$ cells $[96,97]$. Trm cells of the skin are known of their long-term residence in the skin. They patrol their surroundings; the epidermis and papillary dermis, and rapidly respond when they encounter their cognate antigen [98]. They are defined by the cell surface expression of CD69, CD103, CD49a and CD44 [99]. As these cells are able to live in tissues for long time and rapidly evoke immunity reactions against viruses, they were strongly considered candidates for stimulating vitiligo lesional relapse [39]. Trm cells function has been the subject of debate. In some models, these cells sufficiently control viral titres during re-infection with no need for recirculating cells [100, 101]. In other contexts, they mainly synthesise cytokines for effector T cell recruitment from the circulation (Ariotti et al., 2014). However, CD8+ Trm cells are shown to have low cytotoxic potential.

In normal human skin CD8+ Trem cells demonstrated low levels of granzyme B and perforin [102]. Moreover, the effect of CD8+ Trem cells isolated from normal human skin on lysing allogenic target cells were significantly poorer than circulating effector memory $\mathrm{T}$ cells [103]. Trm cells mediate the immune response to melanoma via inhibiting tumour outgrowth instead of tumour elimination, indicating that Trm cells lack cytotoxic ability [104]. Based on their low cytotoxic activity and efficient ability of producing cytokines, Trm cells may be involved in recruitment of effector cells from circulation [39]. In vitiligo mouse model, it was found that blockade of $\mathrm{T}$ cell migration to the skin or depletion of recirculating memory $\mathrm{T}$ cells reversed vitiligo, although the number of Trm cells was not affected [105]. It was therefore concluded that Trm cells cannot independently maintain vitiligo in the absence of recruitment of further $\mathrm{T}$ cells [105]. In this vitiligo mouse model, autoreactive melanocyte-specific CD8+ Trm cells were shown to synthesise IFN- $\gamma$ and CXCL10, probably employing the IFN- $\gamma$-chemokine pathway to maintain vitiligo lesions [105]. Thus, Trm cells are likely to mediate the long-term maintenance and relapse of the disease in patients via cytokinemediated recruitment of circulating T cells [39]. Notably, vitiligo patients with stable disease are considered to have continuing immune response, as evidenced the existence of Trm cells in vitiligo perilesional skin [69, 106]. These may be involved during a flare-up, as previously reported in psoriasis [107].

\section{Humoral Immunity in Vitiligo}

Besides cellular immunity, humoral (antibody-mediated) immunity adds supportive evidence for a pathological role of autoimmunity in vitiligo.

Different antibodies to melanocytes have been identified at significantly elevated levels in the sera of vitiligo 
patients as opposed to healthy controls [108-111], and their levels are directly associated with the extent and activity of vitiligo [109, 112, 113], being present in $93 \%$ of patients with wider depigmentation $(5-10 \%$ of skin area involved) and in only $50 \%$ of patients with minimal pigment loss $(<2 \%$ of skin area involved) [114].

These anti-melanocyte antibodies belong to the immunoglobulin G (IgG) class [111], including subclasses IgG1, IgG2 and IgG3 [115], though IgA anti-melanocyte antibodies have also been detected [116].

Immunoprecipitation studies using melanocyte protein extracts have shown that antibodies in vitiligo patients are most frequently directed to antigens with molecular weights of 35, 40 to 45, 75, 90 and 150-kDa, these being found on the cell surface [117]. Some of these proteins, including those of 40-45, 75, and 150-kDa, appear to be common tissue antigens, whereas the 35 and 90- kDa proteins are preferentially expressed on melanocytes [118]. Additionally, other reports have identified vitiligo antibody targets of 45, 65, 70, 88, and $110-\mathrm{kDa}$, which are specifically expressed in melanocytes [119]. Various melanocyte-associated autoantigens have been reported. Antibodies against tyrosinase, a melanocyte-specific protein, have been extensively detected [120-122], as have antibodies against other proteins of the melanogenic pathway such as L-dopachrome tautomerase, TYRP1, PMEL, albeit at a low prevalence [123-125]. Considering this autoantibody response, rituximab, a monoclonal directed against CD20 protein expressed on the B cell surface, has shown promise in a small clinical trial in vitiligo patients [126]. A variety of circulating organ-specific antibodies against gastric parietal cells, pancreatic islet cells, thyroid and adrenal glands, are common in vitiligo patients' sera, though these are not recognised as major melanocyte antigens [127]. Phage display technology has identified other targets such as melanin-concentrating hormone receptor 1, tyrosine hydroxylase, heat-shock protein 90, osteopontin, ubiquitin-conjugating enzyme, translation-initiation factor 2, GTP-binding protein Rab38, $\gamma$-enolase, $\alpha$-enolase and lamin A [128-130], as well as four novel autoantigens glycoprotein non-metastatic melanoma protein b, melanocortin 1 receptor, OCA2-encoded P protein and GTP-binding protein Rab27A (unpublished data). Vitiligo-associated antibodies are capable of melanocytotoxicity in vitro and in vivo by complement-mediated cytotoxicity and by antibody-dependent cellular cytotoxicity [131, 132]. Melaninconcentrating hormone receptor 1 block the function of the receptor, though it is not known if this affects melanocyte function [133]. Melanocyte expressed of HLA-DR and intercellular adhesion molecule-1 (ICAM1) induced by anti-melanocyte antibodies may make them a target for cytotoxic T cells [134]. Presently, it unclear whether melanocytes are a primary or secondary target of the humoral immunity in vitiligo. Autoantibodies might arise from a genetic susceptibility to immune dysregulation at the $\mathrm{T}$ or $\mathrm{B}$ lymphocyte level, with lack of tolerance to pigment cell antigens, or from an immune response against melanocytes damaged by other mechanisms, such as $\mathrm{T}$ cell destruction [135]. Repigmentation observed in vitiligo patients receiving immunosuppressive treatments supports the notion of an immune-mediated process in vitiligo [13]. Tacrolimus, a reagent that suppresses $\mathrm{T}$ cells by blocking cytokine gene-activating cofactor calcineurin works in vitiligo [136, 137], as do topical corticosteroids, which suppress T lymphocyte activity and B cell antibody responses [138]. Phototherapy, reduces the number of Langerhans cell in the skin and down regulates expression of vitiligo-associated melanocyte antigens [139].

\section{Pathogenic Mechanisms of Autoimmunity in Vitiligo}

The ability of vitiligo-associated antibodies to destroy melanocytes has been demonstrated in vitro by both complement-mediated cytotoxicity and antibody-dependent cellular cytotoxicity [131, 133, 140].

In vivo, the administration of IgG from vitiligo patients into human skin grafted onto nude mice has been shown to induce melanocyte destruction [132]. In a reconstructed epidermis model, sera from 9/13 (69\%) vitiligo patients induced the detachment of melanocytes, although this was not related to disease extent or activity [141]. Vitiligo patient antibodies against MCHR1 were demonstrated to block the function of the receptor [133]. However, it is not known if or how this activity could affect the melanocyte function [133]. Moreover, IgG anti-melanocyte antibodies are able to induce the expression of HLA-DR and ICAM-1 on melanocytes and the release of IL-8 from melanocytes [134]. By enhancing the antigen-presenting activity of melanocytes in this way, they become targets for cytotoxic T cells. Presently, it has not been determined if melanocytes are a primary or secondary target of the humoral immune response in vitiligo. They might 
arise from a genetic susceptibility to immune dysregulation at the $\mathrm{T}$ or B lymphocyte level, leading to lack of tolerance to pigment cell antigens [142]. Alternatively, vitiligo antibodies might originate from an immune response against melanocytes damaged by some other mechanism [142].

Interestingly, the normally intracellular melanocyte antigens TYRP1 and PMEL can be expressed on the cell surface and so can be accessible by antibodies $[143,144]$. In addition, pigment cell antibodies in vitiligo might be secondary to destruction of the melanocyte from another immune cause such as T-cells, but that once triggered the antibodies are themselves destructive to melanocytes. While the potential for cytotoxic CD8+ $\mathrm{T}$ cells to eliminate melanocytes in both vitiligo and melanoma immunotherapy is clear, the exact mechanism that these cells use is not fully understood. Several cytotoxic effector proteins such as perforin, granzyme, Fas ligand and cytokines can be used to destroy target cells [145]. It is believed that cytotoxic T cells mainly use perforin and granzyne as fast-acting method of destroying cancer cells or virus-infected cells, whereas Fas ligand-driven killing mechanism may act as slower-acting alternative process [146]. In fact, several intracellular signaling pathways promote cytotoxic $\mathrm{T}$ cell killing via perforin, granzyme and $\mathrm{F}$ as ligand, and therefore it is currently unclear how these pathways are selectively used by $\mathrm{T}$ cells and how they communicate [145]. Additionally, T cell-mediated killing mechanism in autoimmune vitiligo may differ from that of cancer or viral-infected cells. Therefore, how melanocyte in vitiligo are eliminated is not yet clear, and this requires further studies in order to unveil the exact mechanism involved in details. Melanocytes from perilesional skin of vitiligo patients demonstrates physiological and histological abnormalities which may induce autoimmune reaction against melanocytes. Genes that are implicated in antigen presentation confer a significant risk for the development of vitiligo [147]. One hypothesis suggests that modified proteins called neo-antigen can be extremely immunogenic stimulating an immune response against them, since thymic epithelial cells responsible for $\mathrm{T}$ cell education do not synthesise such proteins [148]. This leads to the formation of highly self-reactive $\mathrm{T}$ cells with high-affinity receptors that target neo-antigens [148]. Melanoma is immunogenic owing to somatic DNA mutation that result in neo-antigen generation [149]. However, self-reactive T cells are unlikely to target mutated proteins in vitiligo, since untransformed melanocytes do not have the ability to mutate their DNA [39]. Several biochemical processes have been involved in neo-antigen formation as well such as deamidation, carbanylation, citrullination, oxidation and alternative mRNA splicing [38]. These processes are implicated in generating neo-antigen in untransformed beta islet cells [38].

\section{Cytokines Imbalance and their Role in Vitiligo Pathogenesis}

Cytokine imbalance has been shown in vitiligo skin [150]. Elevated serum levels of soluble IL-2 receptor, which correlated with disease activity in vitiligo patients, have been reported, as have increased synthesis of IL-6, a cytokine induces ICAM-1 expression on melanocytes which could facilitate leukocyte-melanocyte interaction, as well as elevated levels of IL-8, neutrophils, T lymphocytes, and basophils recruiter [151, 152]. Recently this has been added to by the revelation of elevation of $\mathrm{T}$ helper (Th) 1 (IL-2, interferon (IFN)- $\gamma$, TNF- $\beta$ ), Th2 (IL-4, IL-5, IL-10, IL-13) and Th17 (IL-17, IL-23)-innate cytokines in the serum of all 44 vitiligo patients examined, with a higher ratio of Th1/Th2 cytokines [153]. Expression of the pro-inflammatory cytokine TNF- $\alpha$ is significantly elevated in lesional and peri-lesional vitiligo patient skin, whereas a variety of melanogenic mediators such as endothelin-1, stem cell factor, basic fibroblastic growth factor and granulocyte monocyte-colony stimulating factor are expressed at lower levels in vitiliginous lesions [154]. Recently it has been shown that melanocyte adhesion is disrupted in vitiligo skin through increased levels of MMP-9, produced by keratinocytes in response to IFN- $\gamma$ and TNF- $\alpha$, and disturbing E-cadherin on the pigment cells [155]. Both human patients and a mouse model of vitiligo, show high levels of IFN- $\gamma$, the cytokine required for the cutaneous recruitment of melanocyte-specific autoreactive CD8+ T lymphocytes, and of IFN- $\gamma$-induced cytokine CXCL10, and its receptor CXCR3, found on autoreactive CD8+ T cells [71]. Knocking out CXCR3 or blocking CXCL10 action prevents and reverses depigmentation in vitiligo [76].

\section{Malignant Melanoma-Associated Vitiligo}

Malignant melanoma is a type of skin cancer resulted from uncontrolled growth of melanocytes. Although the exact mechanism implicated in the pathogenesis of malignant melanoma-associated vitiligo is still unclear, the immune reactivity against malignant melanoma cells, especially CD $8+\mathrm{T}$ cells, is thought to play a critical role 
in vitiligo development $[156,157]$. Malignant melanoma-associated vitiligo may arise from immune response directed against malignant melanoma-associated antigens expressed by both melanocytes and malignant melanoma cells. Indeed, antibodies reactive to tyrosinase [158], TYRP1, dopachrome tautomerase and Pmel17 [159] have been found in some malignant melanoma patient sera. Malignant melanoma studies showed that these melanocyte specific-antigens were recognised by self-reactive CD8+ T cells [160]. Following immunotherapy for metastatic malignant melanoma, enhanced efficacy is associated with CD8+ T cells. Immunotherapy for malignant melanoma involves blocking T-cell checkpoint inhibitors, which interfere with $\mathrm{T}$ cell tolerance in tissues, and adoptive cell therapy, which expands $\mathrm{T}$ cells that infiltrate autologous tumor ex vivo for therapeutic reinjection into melanoma patients [39]. Importantly, tumour infiltration with CD8+ $\mathrm{T}$ cells is vital in the effectiveness of both strategies [161], and these cells are thought to regulate malignant melanoma via perforin-dependent cytolysis [145]. New-onset vitiligo is commonly triggered by malignant melanoma therapy, and this occurs in about $4 \%$ such patients who are treated with immunotherapy [162]. Notably, vitiligo patches initiated by malignant melanoma immunotherapy are packed with CD8+ T cells that are specific to melanocytes, similar to idiopathic vitiligo patches [163]. Thus, CD8+ T cells are crucial to both the eradication of malignant melanoma and the pathogenesis of vitiligo. Therefore, the immune response in malignant melanoma patients which causes melanocyte damage is suggested to be cell-mediated, driven by CD $8+\mathrm{T}$ cells and not by a humoral response. Thus, CD8+ T cells are crucial to both the eradication of malignant melanoma and the pathogenesis of vitiligo. Melanocyte-specific antibodies in malignant melanoma patients are likely to arise as a secondary immune response after melanocyte destruction via cell-mediated effects. Furthermore, the serum titres of malignant melanoma-related antibodies are low and their levels do not differ in patients with and without malignant melanoma-associated vitiligo. Vitiligo-like lesions in malignant melanoma patients receiving immunotherapy are considered as a good prognostic factor and have been correlated with a longer survival in these patients [164]. Development of vitiligo during treatment of malignant melanoma can be used as a clinical indication to predict and maintain the response [164].

\section{Genetic Factors}

Genetic involvement in vitiligo is obvious from a simple examination of family histories: $15-20 \%$ of vitiligo patients have at least one affected first-grade relative [165]. However, vitiligo does not show a Mendelian mechanism of inheritance, but is the polygenic with multiple susceptibility loci [147]. The concordance rate in monozygotic twins is $23 \%$, suggesting involvement of non-genetic factors [166]. Genome-wide association studies have revealed that approximately half of vitiligo susceptibility genes encode immune-regulatory proteins, while the remainder encode melanocyte-specific proteins [147]. Several studies have shown that multiple loci contribute to vitiligo susceptibility (Table 1). An observed association between HLA types and vitiligo, and other autoimmune disorders, can be elucidated by several pathways that ultimately result in disruption in self-antigen recognition (Jin et al., 2012a). This can lead to autoreactive $\mathrm{T}$ cell development and/or failure to produce effective Tregs population [60]. Genome-wide association studies have also reported a subset of other immune regulatory genes that are also key mediators of adaptive immunity such as CD80 (activation of $\mathrm{T}$ cells), cytotoxic T lymphocyte antigen-4; CTLA4 (inhibition of T cells), GZMB (cytotoxicity of T cells), forkhead box protein P3; FOXP3(development and function of regulatory $\mathrm{T}$ cells), lymphoid protein tyrosine phosphatase non-receptor type 22; PTPN22(down-regulation of T cell activation) and arginine-glutamic acid dipeptide repeats protein; RERE (regulation of cell apoptosis) [167]. An association of vitiligo with genes that play a role in innate immunity, such as NACHT leucine-rich-repeat protein 1 (NLRP1), interferon-induced helicase C domain 1 (IFIH1) and caspase-7 (CASP7), has also been found in genome-wide association studies [168]. In addition to immune regulatory genes, several genes that are only expressed in melanocytes and involved in melanocyte function have been identified as vitiligo susceptibility loci. These include TYR, PMEL, melanocortin 1 receptor (MC1R ), OCA2 [169]. Such genes encode for enzymes or proteins recognised as autoantigens in vitiligo, facilitating an anti-melanocyte autoimmune response $[122,124]$.

Table 1: A summary of genes associated with susceptibility to vitiligo 


\begin{tabular}{|c|c|c|c|}
\hline Type & Gene & Protein & Fur \\
\hline \multirow[t]{3}{*}{ HLA } & $H L A-A$ & HLA class I histocompatibility antigen, A & $\mathrm{Pel}$ \\
\hline & $H L A-D R B 1$ and $D Q A 1$ & HLA class II histocompatibility antigen, DRB1 and DQA1 & $\mathrm{Pel}$ \\
\hline & HLA class III & HLA class III histocompatibility antigen & Inve \\
\hline \multirow[t]{25}{*}{ Immune- regulatory } & AIRE & Autoimmune regulator & Ma \\
\hline & BACH2 & Transcription regulator protein $\mathrm{BACH} 2$ & $\mathrm{BC}$ \\
\hline & C1QTNF6 & Complement C1q tumour necrosis factor-related protein 6 & Ind \\
\hline & $C A S P^{r}$ & Caspase-7 & Exe \\
\hline & CCR6 & Chemokine-cytokine receptor 6 & $\operatorname{Re}$ \\
\hline & $C D 44$ & CD44 antigen & Inv \\
\hline & $C D 80$ & T-lymphocyte activation antigen CD80 & $\mathrm{Co}$ \\
\hline & CLNK & Cytokine-dependent hematopoietic cell linker & Pos \\
\hline & CTLA4 & Cytotoxic T-lymphocyte protein 4 & $\operatorname{Inh}$ \\
\hline & $C X C R 5$ & C-X-C chemokine receptor type 5 & Inv \\
\hline & $F A S L G$ & FAS ligand & $\operatorname{Re}$ \\
\hline & FOXP1 & Forkhead box protein P1 & $\operatorname{Re}$ \\
\hline & FOXP3 & Forkhead box protein P3 & Rę \\
\hline & $G Z M B$ & Granzyme B & $\mathrm{Me}$ \\
\hline & IFIH1 & Interferon-induced helicase $\mathrm{C}$ domain 1 & Rę \\
\hline & $I K Z F 4$ & Zinc finger protein Eos & Req \\
\hline & $I L 2 R A$ & Interleukin-2 receptor subunit alpha & \\
\hline & NLRP1 & NACHT leucine-rich-repeat protein 1 & Req \\
\hline & PTPN22 & Lymphoid protein tyrosine phosphatase non-receptor type 22 & \\
\hline & SH2B3 & SH2B adapter protein 3 & \\
\hline & $S L A$ & Src-like-adapter & \\
\hline & TOB2 & Protein TOB2 & \\
\hline & $T S L P$ & Thymic stromal lymphopoietin & \\
\hline & UBASHЗА & Ubiquitin-associated and SH3 domain-containing A protein & \\
\hline & $X B P 1$ & $\mathrm{X}$-box-binding protein 1 & \\
\hline \multirow{7}{*}{ Melanocyte function } & $A S P$ & Agouti signalling protein & \\
\hline & FOXD3 & Forkhead box D3 & \\
\hline & $M C 1 R$ & Melanocortin 1 receptor & \\
\hline & $O C A 2$ & OCA2 gene & \\
\hline & $P M E L$ & Melanocyte-specific protein PMEL & \\
\hline & $T Y R$ & Tyrosinase & \\
\hline & ZMIZ1 & Zinc finger protein MIZ type 1 & \\
\hline \multirow[t]{6}{*}{ Metabolism-related genes } & $A C E$ & Angiotensin-converting enzyme & $\operatorname{Re}$ \\
\hline & $C A T$ & Catalase & \\
\hline & $E D N-1$ & Endothelin-1 & \\
\hline & $L P P$ & Lipoma-preferred partner & \\
\hline & $R E R E$ & Arginine-glutamic acid dipeptide repeats protein & \\
\hline & RNASET2 & Ribonuclease T2 & \\
\hline
\end{tabular}

\section{Neuronal Theory}

Neuronal elements were originally thought to have a role in vitiligo through catecholamine released from epidermal nerve endings which might be cytotoxic to melanocytes or by autonomic dysfunction producing pigment cell destruction [203, 204]. Clinical pointers towards neural involvement included the distribution along blaschkoid lines in segmental vitligo, and the occasional observation of a true dermatomal appearance, e.g. in the trigeminal areas $[167,204]$. 
Ultrastructurally vitiligo skin shows degeneration of fine cutaneous nerves in $42 \%$ of cases, with Schwann cells showing thickened basement membrane in $75 \%$ of instances and axonal damage in a half $[203,205]$. Changes in neuropeptides, notably neuropeptide $\mathrm{Y}$, are evident at the margins of vitiligo patches [205]. This led to the postulation that neuropeptides, potentially neuropeptide $\mathrm{Y}$, which has effects on the immune system through receptors located on several immunologically active cells including T cells, NK cells, dendritic cells, granulocytes, and macrophages, released from nerve ending release next to melanocytes, could provoke a local immune reaction and melanocyte destruction [206, 207]. Treg cells, seen as central to melanocyte destruction in vitiligo, can be induced by vasoactive intestinal polypeptide, and can alter the Th1/cytotoxic T cell (Tc) 1 balance that is skewed in vitiligo [208]. Hence, the neural and neuro-endocrine systems, neuropeptides and neurotransmitters, interacting with the immune systems, need to be taken into account in the

causation of vitiligo [209].

\section{Convergence Theory}

The convergence theory attempts to link together the potential causal mechanisms of vitiligo [210]. It suggests multiple sequential stages in pathogenesis beginning with an elicitation stage perhaps due to mechanical friction and skin trauma, emotional stresses, chemical exposure or imbalances in endogenous neural factors, metabolites, cytokines or hormones [5, 206, 211-214]. Such factors, in an individual whose genetic make-up predisposes to immune activation and melanocyte destruction, it is proposed result in oxidative stress within melanocytes which subsequently express HSP70 and chaperoned melanocyte antigens, presented by dendritic cells to $\mathrm{T}$ cells in regional lymph nodes, resulting in proliferation of melanocyte-specific cytotoxic $\mathrm{T}$ cells and melanocyte destruction - the stage of immune activation [54, 135, 166].

Absent or reduced fully-functional skin-infiltrating Tregs contribute to the on-going immune response and disease spread [86]. Antibodies against melanocyte-specific proteins such as tyrosinase, generated in response to melanocyte destruction, damage pigment cells by activating complement or by antibody-dependent cellular cytotoxicity $[122,133]$.

\section{Conclusion and Prospects}

Sufficient is now understood about the pathogenesis of vitiligo to permit targeted pharmacological intervention at the appropriate immunological steps. However, the exact modus by which the genetic interacts with the environment, and with the immune system still requires considerable elucidation. What can be said is that both environmental factors and cell-intrinsic defects instigate stress responses in melanocytes, resulting in the synthesis of DAMPs that elicit innate immune cells, which in turn activate adaptive immunity that ultimately targets melanocytes. A genetic predisposition to autoimmunity may underlie inappropriate immune responses in vitiligo, but immune responses may occur secondarily as a result of melanocyte damage by other factors, as when autoantibodies have been observed directed against intracellular pigment cell proteins exposure of cryptic epitopes and protein modification occurring during apoptosis [215]. Following processing by dendritic cells, antigenic proteins can be presented to either autoreactive $\mathrm{T}$ cells, which evaded clonal deletion, or to naïve $\mathrm{T}$ cells, which have not been tolerised against cryptic epitopes [216]. In consequence, antibodies can be secreted following autoreactive B cell stimulation by activated autoreactive CD4+ T lymphocytes [216], which may then act to further aggravate vitiligo. However, it is possible that antibodies play no part in the pathogenesis of vitiligo, but might indicate the existence of autoreactive anti-melanocyte $\mathrm{T}$ cells are capable of destroying melanocytes, a scenario that merits further investigation.

\section{References}

1. Ezzedine, K., et al., Revised classification/nomenclature of vitiligo and related issues: the Vitiligo Global Issues Consensus Conference. Pigment Cell Melanoma Res, 2012. 25 (3): p. E1-13.

2. Manga, P., N. Elbuluk, and S.J. Orlow, Recent advances in understanding vitiligo. F1000Res, 2016. 5 : p. 2234 .

3. Al Abadie, M.S. and D.J. Gawkrodger, Integrating neuronal involvement into the immune and genetic 
paradigm of vitiligo. Clin Exp Dermatol, 2020: p. doi: 10.1111/ced.14490.

4. Zhang, Y., et al., The Prevalence of vitiligo: a meta-analysis. Plos One, 2016.11 (9): p. e0163806.

5. Kent, G. and M. Al'Abadie, Psychologic effects of vitiligo: a critical incident analysis. J Am Acad Dermatol, 1996. 35 (6): p. 895-8.

6. Nogueira, L.S., P.C. Zancanaro, and R.D. Azambuja, Vitiligo and emotions. An Bras Dermatol, 2009. 84 (1): p. $41-5$.

7. Kostopoulou, P., et al., Objective vs. subjective factors in the psychological impact of vitiligo: the experience from a French referral centre. Br J Dermatol, 2009. 161 (1): p. 128-33.

8. Parsad, D., S. Dogra, and A.J. Kanwar, Quality of life in patients with vitiligo. Health Qual Life Outcomes, 2003. 1 : p. 58.

9. Porter, J., et al., Personal responses of patients to vitiligo: the importance of the patient-physician interaction. Arch Dermatol, 1978.114 (9): p. 1384-5.

10. Sukan, M. and F. Maner, The problems in sexual functions of vitiligo and chronic urticaria patients. J Sex Marital Ther, 2007.33 (1): p. 55-64.

11. Alikhan, A., et al., Vitiligo: a comprehensive overview Part I. Introduction, epidemiology, quality of life, diagnosis, differential diagnosis, associations, histopathology, etiology, and work-up. J Am Acad Dermatol, 2011. 65 (3): p. 473-91.

12. Parsad, D., et al., Dermatology Life Quality Index score in vitiligo and its impact on the treatment outcome. Br J Dermatol, 2003.148 (2): p. 373-4.

13. Ezzedine, K., et al., Vitiligo. The Lancet, 2015.386 (9988): p. 74-84.

14. Boissy, R.E. and P. Manga, On the etiology of contact/occupational vitiligo. Pigment Cell Res, 2004. 17 (3): p. 208-14.

15. Karagaiah, P., et al., Emerging drugs for the treatment of vitiligo. Expert Opin Emerg Drugs, 2020. 25 (1): p. $7-24$.

16. Tobin, D.J., et al., Melanocytes are not absent in lesional skin of long duration vitiligo. J Pathol, 2000. 191 (4): p. 407-16.

17. Ackerman, A.B., H. Kerl, and J. Sánchez, A clinical atlas of 101 common skin diseases : with histopathologic correlation. 2000, New York: Ardor Scribendi.

18. van den Wijngaard, R., et al., Local immune response in skin of generalized vitiligo patients. Destruction of melanocytes is associated with the prominent presence of CLA + T cells at the perilesional site. Lab Invest, 2000. 80 (8): p. 1299-309.

19. Puri, N., M. Mojamdar, and A. Ramaiah, In vitro growth characteristics of melanocytes obtained from adult normal and vitiligo subjects. J Invest Dermatol, 1987. 88 (4): p. 434-438.

20. Puri, N., M. Mojamdar, and A. Ramaiah, Growth defects of melanocytes in culture from vitiligo subjects are spontaneously corrected in vivo in repigmenting subjects and can be partially corrected by the addition of fibroblast-derived growth factors in vitro. Arch Dermatol Res, 1989.281 (3): p. 178-84.

21. Dell'Anna, M.L., et al., Antioxidants and narrow band-UVB in the treatment of vitiligo: a double-blind placebo controlled trial. Clin Exp Dermatol, 2007. 32 (6): p. 631-6.

22. Schallreuter, K.U., et al., In vivo and in vitro evidence for hydrogen peroxide (H2O2) accumulation in the epidermis of patients with vitiligo and its successful removal by a UVB-activated pseudocatalase. J Investig Dermatol Symp Proc, 1999. 4 (1): p. 91-6. 
23. Medrano, E.E. and J.J. Nordlund, Successful culture of adult human melanocytes obtained from normal and vitiligo donors. J Invest Dermatol, 1990. 95 (4): p. 441-5.

24. Dell'Anna, M.L., et al., Membrane lipid alterations as a possible basis for melanocyte degeneration in vitiligo. J Invest Dermatol, 2007.127 (5): p. 1226-33.

25. Shalbaf, M., et al., Presence of epidermal allantoin further supports oxidative stress in vitiligo. Exp Dermatol, 2008.17 (9): p. 761-70.

26. Maresca, V., et al., Increased sensitivity to peroxidative agents as a possible pathogenic factor of melanocyte damage in vitiligo. J Invest Dermatol, 1997. 109 (3): p. 310-3.

27. Jimbow, K., et al., Increased sensitivity of melanocytes to oxidative stress and abnormal expression of tyrosinase-related protein in vitiligo. Br J Dermatol, 2001. 144 (1): p. 55-65.

28. Gawkrodger, D.J., Pseudocatalase and narrowband ultraviolet B for vitiligo: clearing the picture. Br J Dermatol, 2009. 161 (4): p. 721-2.

29. Spielvogel, R.a.K., GR., Pigmentary disorders of the skin. Lever's Histopathology of the Skin, 2005(D. E. Elder, R. Elenitsas, B. L. Johansson and G. F. Murphy. Philadelphia, Lippincott Williams \& Wilkins:): p. $705-713$.

30. Gilhar, A., et al., Vitiligo and idiopathic guttate hypomelanosis. Repigmentation of skin following engraftment onto nude mice. Arch Dermatol, 1989. 125 (10): p. 1363-6.

31. Li, W., S. Wang, and A.-e. Xu, Role of in vivo reflectance confocal microscopy in determining stability in vitiligo: a preliminary study. Indian J Dermatol, 2013. 58 (6): p. 429-32.

32. Rashighi, M. and J.E. Harris, Vitiligo pathogenesis and emerging treatments. Dermatol Clin, 2017. 35 (2): p. 257-65.

33. Sravani, P.V., et al., Determination of oxidative stress in vitiligo by measuring superoxide dismutase and catalase levels in vitiliginous and non-vitiliginous skin. Indian J Dermatol Venereol Leprol, 2009.75 (3): p. 268-71.

34. Schallreuter, K.U., et al., Epidermal $\mathrm{H}(2) \mathrm{O}(2)$ accumulation alters tetrahydrobiopterin (6BH4) recycling in vitiligo: identification of a general mechanism in regulation of all 6BH4-dependent processes? J Invest Dermatol, 2001. 116 (1): p. 167-74.

35. Xie, H., et al., Vitiligo: how do oxidative stress-induced autoantigens trigger autoimmunity? J Dermatol Sci, 2016. 81 (1): p. 3-9.

36. Wang, Y., S. Li, and C. Li, Perspectives of new advances in the pathogenesis of vitiligo: from oxidative stress to autoimmunity. Medical science monitor : international medical journal of experimental and clinical research, 2019. 25 : p. 1017-1023.

37. Ghanem, G. and J. Fabrice, Tyrosinase related protein 1 (TYRP1/gp75) in human cutaneous melanoma. Mol Oncol, 2011. 5 (2): p. 150-55.

38. James, E.A., M. Pietropaolo, and M.J. Mamula, Immune recognition of $\beta$-cells: neoepitopes as key players in the loss of tolerance. Diabetes, 2018. 67 (6): p. 1035-1042.

39. Frisoli, M.L., K. Essien, and J.E. Harris, Vitiligo: mechanisms of pathogenesis and treatment. Annu Rev Immunol, 2020. 38 : p. 621-648.

40. Toosi, S., S.J. Orlow, and P. Manga, Vitiligo-inducing phenols activate the unfolded protein response in melanocytes resulting in upregulation of IL6 and IL8. J Invest Dermatol, 2012. 132 (11): p. 2601-9.

41. Doss, R.W., et al., Heat shock protein-70 expression in vitiligo and its relation to the disease activity. Indian J. Dermatol, 2016.61 (4): p. 408-412. 
42. Levandowski, C.B., et al., NLRP1 haplotypes associated with vitiligo and autoimmunity increase interleukin-1beta processing via the NLRP1 inflammasome. Proc Natl Acad Sci U S A, 2013. 110 (8): p. 2952-6.

43. Richmond, J.M., M.L. Frisoli, and J.E. Harris, Innate immune mechanisms in vitiligo: danger from within. Curr Opin Immunol, 2013.25 (6): p. 676-82.

44. Yu, R., et al., Transcriptome analysis reveals markers of aberrantly activated innate immunity in vitiligo lesional and non-lesional skin. PLoS ONE, 2012. 7 (12): p. e51040.

45. Denman, C.J., et al., HSP70i accelerates depigmentation in a mouse model of autoimmune vitiligo. J Invest Dermatol, 2008. 128 (8): p. 2041-8.

46. Mosenson, J.A., et al., Mutant HSP70 reverses autoimmune depigmentation in vitiligo. Sci Transl Med, 2013. 5 (174): p. $174 \mathrm{ra} 28$.

47. Zhang, H., et al., Fusion protein of ATPase domain of Hsc70 with TRP2 acting as a tumor vaccine against B16 melanoma. Immunol Lett, 2006.105 (2): p. 167-73.

48. Kroll, T.M., et al., 4-Tertiary butyl phenol exposure sensitizes human melanocytes to dendritic cellmediated killing: relevance to vitiligo. J Invest Dermatol, 2005. 124 (4): p. 798-806.

49. Mosenson, J.A., et al., Preferential secretion of inducible HSP70 by vitiligo melanocytes under stress. Pigment Cell Melanoma Res, 2014.27 (2): p. 209-20.

50. Sun, L., W. Liu, and L.J. Zhang, The role of Toll-like receptors in skin host defense, psoriasis, and atopic dermatitis. J Immunol Res, 2019. 2019 : p. 1824624.

51. Basak, P.Y., et al., Evaluation of activatory and inhibitory natural killer cell receptors in non-segmental vitiligo: a flow cytometric study. J Eur Acad Dermatol Venereol, 2008. 22 (8): p. 970-6.

52. Henning, S.W., et al., HSP70i(Q435A)-encoding DNA repigments vitiligo lesions in Sinclair swine. J Invest Dermatol, 2018.138 (12): p. 2531-2539.

53. Rodrigues, M., et al., New discoveries in the pathogenesis and classification of vitiligo. J Am Acad Dermatol, 2017. 77 (1): p. 1-13.

54. van den Boorn, J.G., et al., Skin-depigmenting agent monobenzone induces potent T-cell autoimmunity toward pigmented cells by tyrosinase haptenation and melanosome autophagy. J Invest Dermatol, 2011.131 (6): p. $1240-51$.

55. Li, S., et al., Activated NLR family pyrin domain containing 3 (NLRP3) inflammasome in keratinocytes promotes cutaneous T-cell response in patients with vitiligo. J Allergy Clin Immunol, 2020.145 (2): p. 632-645.

56. Bauernfeind, F.G., et al., NF-kappaB activating pattern recognition and cytokine receptors license NLRP3 inflammasome activation by regulating NLRP3 expression. Journal of immunology (Baltimore, Md. : 1950), 2009. 183 (2): p. 787-791.

57. Zhou, R., et al., A role for mitochondria in NLRP3 inflammasome activation. Nature, 2011. 469 (7329): p. $221-225$.

58. Thornberry, N.A., et al., A novel heterodimeric cysteine protease is required for interleukin-1ßprocessing in monocytes. Nature, 1992.356 (6372): p. 768-774.

59. Gu, Y., et al., Activation of interferon-gamma inducing factor mediated by interleukin-1beta converting enzyme. Science, 1997.275 (5297): p. 206-9.

60. Speeckaert, R. and N. van Geel, Vitiligo: an update on pathophysiology and treatment options. Am J Clin Dermatol, 2017. 
61. Badri, A.M., et al., An immunohistological study of cutaneous lymphocytes in vitiligo. J Pathol, 1993. 170 (2): p. 149-55.

62. Wankowicz-Kalinska, A., et al., Immunopolarization of CD4+ and CD8+ T cells to type-1-like is associated with melanocyte loss in human vitiligo. Lab Invest, 2003. 83 (5): p. 683-95.

63. Le Poole, I.C., et al., Presence of T cells and macrophages in inflammatory vitiligo skin parallels melanocyte disappearance. Am J Pathol, 1996. 148 (4): p. 1219-28.

64. Ogg, G.S., et al., High frequency of skin-homing melanocyte-specific cytotoxic T lymphocytes in autoimmune vitiligo. J Exp Med, 1998.188 (6): p. 1203-8.

65. Strassner, J.P., et al., Suction blistering the lesional skin of vitiligo patients reveals useful biomarkers of disease activity. J Am Acad Dermatol, 2017. 76 (5): p. 847-55.

66. van Geel, N.A., et al., First histopathological and immunophenotypic analysis of early dynamic events in a patient with segmental vitiligo associated with halo nevi. Pigment Cell Melanoma Res, 2010.23 (3): p. $375-84$.

67. Palermo, B., et al., Specific cytotoxic T lymphocyte responses against Melan-A/MART1, tyrosinase and gp100 in vitiligo by the use of major histocompatibility complex/peptide tetramers: the role of cellular immunity in the etiopathogenesis of vitiligo. J Invest Dermatol, 2001.117 (2): p. 326-32.

68. van den Boorn, J.G., et al., Autoimmune destruction of skin melanocytes by perilesional T cells from vitiligo patients. J Invest Dermatol, 2009. 129 (9): p. 2220-32.

69. Boniface, K., et al., Vitiligo skin is imprinted with resident memory CD8 T cells expressing CXCR3. J Invest Dermatol, 2018.138 (2): p. 355-64.

70. Grimes, P.E., et al., Topical tacrolimus therapy for vitiligo: therapeutic responses and skin messenger RNA expression of proinflammatory cytokines. J Am Acad Dermatol, 2004. 51 (1): p. 52-61.

71. Rashighi, M., et al., CXCL10 is critical for the progression and maintenance of depigmentation in a mouse model of vitiligo. Sci Transl Med, 2014. 6 (223): p. 223ra23.

72. Bertolotti, A., et al., Type I interferon signature in the initiation of the immune response in vitiligo. Pigment Cell Melanoma Res, 2014. 27 (3): p. 398-407.

73. Wang, X.X., et al., Increased expression of CXCR3 and its ligands in patients with vitiligo and CXCL10 as a potential clinical marker for vitiligo. Br J Dermatol, 2016. 174 (6): p. 1318-26.

74. Harris, J.E., et al., A mouse model of vitiligo with focused epidermal depigmentation requires IFNgamma for autoreactive CD8(+) T-cell accumulation in the skin. J Invest Dermatol, 2012.132 (7): p. 1869-76.

75. Richmond, J.M., et al., Keratinocyte-derived chemokines orchestrate T-cell positioning in the epidermis during vitiligo and may serve as biomarkers of disease. J Invest Dermatol, 2017. 137 (2): p. 350-358.

76. Harris, J.E., et al., Rapid skin repigmentation on oral ruxolitinib in a patient with coexistent vitiligo and alopecia areata (AA). J Am Acad Dermatol, 2016. 74 (2): p. 370-1.

77. Frisoli, M.L. and J.E. Harris, Vitiligo: mechanistic insights lead to novel treatments. J Allergy Clin Immunol, 2017. 140 (3): p. 654-662.

78. Lahl, K., et al., Selective depletion of Foxp3+ regulatory T cells induces a scurfy-like disease. J Exp Med, 2007. 204 (1): p. 57-63.

79. Eby, J.M., et al., Immune responses in a mouse model of vitiligo with spontaneous epidermal de- and repigmentation. Pigment Cell Melanoma Res, 2014. 27 (6): p. 1075-85. 
80. Gregg, R.K., et al., Mechanisms of spatial and temporal development of autoimmune vitiligo in tyrosinase-specific TCR transgenic mice. Journal of immunology (Baltimore, Md. : 1950), 2010. 184 (4): p. 1909-1917.

81. Chatterjee, S., et al., A quantitative increase in regulatory $\mathrm{T}$ cells controls development of vitiligo. J Invest Dermatol, 2014.134 (5): p. 1285-94.

82. Eby, J.M., et al., CCL22 to activate Treg migration and suppress depigmentation in vitiligo. The Journal of investigative dermatology, 2015. 135 (6): p. 1574-1580.

83. Miao, X., et al., PD-L1 reverses depigmentation in Pmel-1 vitiligo mice by increasing the abundance of Tregs in the skin. Scientific Reports, 2018. 8 (1): p. 1605.

84. Lili, Y., et al., Global activation of CD8+ cytotoxic T lymphocytes correlates with an impairment in regulatory $\mathrm{T}$ cells in patients with generalized vitiligo. PLoS One, 2012. 7 (5): p. e37513.

85. Klarquist, J., et al., Reduced skin homing by functional Treg in vitiligo. Pigment Cell Melanoma Res, 2010. 23 (2): p. 276-86.

86. Ben Ahmed, M., et al., Functional defects of peripheral regulatory $\mathrm{T}$ lymphocytes in patients with progressive vitiligo. Pigment Cell Melanoma Res, 2012. 25 (1): p. 99-109.

87. Terras, S., et al., Immunohistochemical analysis of FOXP3+ regulatory T cells in healthy human skin and autoimmune dermatoses. Int J Dermatol, 2014. 53 (3): p. 294-9.

88. Abdallah, M., et al., Assessment of tissue FoxP3+, CD4+ and CD8+ T-cells in active and stable nonsegmental vitiligo. Int J Dermatol, 2014. 53 (8): p. 940-6.

89. Maeda, Y., et al., Detection of self-reactive CD8+ T cells with an anergic phenotype in healthy individuals. Science, 2014.346 (6216): p. 1536-40.

90. Zhen, Y., et al., Enhanced Th1 and Th17 responses in peripheral blood in active non-segmental vitiligo. Arch Dermatol Res, 2016.308 (10): p. 703-710.

91. Wang, C.Q., et al., Th17 cells and activated dendritic cells are increased in vitiligo lesions. PLoS One, 2011. 6 (4): p. e18907.

92. Martins, C., et al., Phenotype and function of circulating memory T cells in human vitiligo. Br J Dermatol, 2020. 183 (5): p. 899-908.

93. Matos, T.R., Is targeting circulating $\mathrm{T}$ blood cells a therapeutic option for vitiligo? $\mathrm{Br} \mathrm{J}$ Dermatol, 2020. 183 (5): p. 803.

94. Cavalié, M., et al., Maintenance therapy of adult vitiligo with $0.1 \%$ tacrolimus ointment: a randomized, double blind, placebo-controlled study. J Invest Dermatol, 2015. 135 (4): p. 970-974.

95. Sitek, J.C., M. Loeb, and J.R. Ronnevig, Narrowband UVB therapy for vitiligo: does the repigmentation last? J Eur Acad Dermatol Venereol, 2007. 21 (7): p. 891-6.

96. Mueller, S.N., et al., Memory T cell subsets, migration patterns, and tissue residence. Annual Review of Immunology, 2013. 31 (1): p. 137-161.

97. Steinbach, K., I. Vincenti, and D. Merkler, Resident-memory T cells in tissue-restricted immune responses: for better or worse? Frontiers in immunology, 2018. 9 : p. 2827-2827.

98. Dijkgraaf, F.E., et al., Tissue patrol by resident memory CD8+ T cells in human skin. Nature Immunology, 2019. 20 (6): p. 756-764.

99. Topham, D.J. and E.C. Reilly, Tissue-resident memory CD8+ T cells: from phenotype to function. Frontiers in Immunology, 2018.9 (515). 
100. Jiang, X., et al., Skin infection generates non-migratory memory CD8+ T(RM) cells providing global skin immunity. Nature, 2012.483 (7388): p. 227-31.

101. Mackay, L.K., et al., Long-lived epithelial immunity by tissue-resident memory T (TRM) cells in the absence of persisting local antigen presentation. Proc Natl Acad Sci U S A, 2012.109 (18): p. 7037-42.

102. Seidel, J.A., et al., Skin resident memory CD8(+) T cells are phenotypically and functionally distinct from circulating populations and lack immediate cytotoxic function. Clin Exp Immunol, 2018.194 (1): p. 79-92.

103. McMaster, S.R., et al., Airway-resident memory CD8 T cells provide antigen-specific protection against respiratory virus challenge through rapid IFN- $\gamma$ production. Journal of immunology (Baltimore, Md. : 1950), 2015. 195 (1): p. 203-209.

104. Malik, B.T., et al., Resident memory $\mathrm{T}$ cells in the skin mediate durable immunity to melanoma. Science immunology, 2017. 2 (10): p. eaam6346.

105. Richmond, J.M., et al., Resident memory and recirculating memory $\mathrm{T}$ cells cooperate to maintain disease in a mouse model of vitiligo. The Journal of investigative dermatology, 2019. 139 (4): p. 769-778.

106. Richmond, J.M., et al., Antibody blockade of IL-15 signaling has the potential to durably reverse vitiligo. Science Translational Medicine, 2018. 10 (450): p. eaam7710.

107. Matos, T.R., et al., Clinically resolved psoriatic lesions contain psoriasis-specific IL-17-producing $\alpha \beta \mathrm{T}$ cell clones. The Journal of clinical investigation, 2017. 127 (11): p. 4031-4041.

108. Naughton, G.K., M. Eisinger, and J.C. Bystryn, Antibodies to normal human melanocytes in vitiligo. J Exp Med, 1983. 158 (1): p. 246-51.

109. Naughton, G.K., D. Reggiardo, and J.C. Bystryn, Correlation between vitiligo antibodies and extent of depigmentation in vitiligo. J Am Acad Dermatol, 1986. 15 (5 Pt 1): p. 978-81.

110. Rocha, I.M., et al., Recognition of melanoma cell antigens with antibodies present in sera from patients with vitiligo. Int J Dermatol, 2000. 39 (11): p. 840-3.

111. Farrokhi, S., et al., Assessment of the immune system in 55 Iranian patients with vitiligo. J Eur Acad Dermatol Venereol, 2005.19 (6): p. 706-11.

112. Harning, R., J. Cui, and J.C. Bystryn, Relation between the incidence and level of pigment cell antibodies and disease activity in vitiligo. J Invest Dermatol, 1991. 97 (6): p. 1078-80.

113. Yu, H.S., C.H. Kao, and C.L. Yu, Coexistence and relationship of antikeratinocyte and antimelanocyte antibodies in patients with non-segmental-type vitiligo. J Invest Dermatol, 1993. 100 (6): p. 823-8.

114. Abu Tahir, M., et al., Current remedies for vitiligo. Autoimmun Rev, 2010. 9 (7): p. 516-20.

115. Xie, P., W. Geoghegan, and R. Jordon. Vitiligo autoantibodies. Studies of subclass distribution and complement activation. in J Invest Dermatol. 1991. BLACKWELL PUBLISHING INC 350 MAIN ST, MALDEN, MA 02148 USA.

116. Aronson, P.J. and K. Hashimoto, Association of IgA anti-melanoma antibodies in the sera of vitiligo patients with active disease. J Invest Dermatol, 1987. 88 (475).

117. Zhu, M.C., et al., Detection of serum anti-melanocyte antibodies and identification of related antigens in patients with vitiligo. Genet Mol Res, 2015. 14 (4): p. 16060-73.

118. Cui, J., Y. Arita, and J.C. Bystryn, Characterization of vitiligo antigens. Pigment Cell Res, 1995. 8 (1): p. 53-9.

119. Park, Y.K., et al., Identification of autoantibody to melanocytes and characterization of vitiligo antigen in vitiligo patients. J Dermatol Sci, 1996. 11 (2): p. 111-20. 
120. Song, Y.H., et al., The role of tyrosinase in autoimmune vitiligo. Lancet, 1994. 344 (8929): p. 1049-52.

121. Baharav, E., et al., Tyrosinase as an autoantigen in patients with vitiligo. Clin Exp Immunol, 1996. 105 (1): p. 84-8.

122. Kemp, E.H., et al., Detection of tyrosinase autoantibodies in patients with vitiligo using 35S-labeled recombinant human tyrosinase in a radioimmunoassay. J Invest Dermatol, 1997. 109 (1): p. 69-73.

123. Kemp, E.H., et al., Immunoprecipitation of melanogenic enzyme autoantigens with vitiligo sera: evidence for cross-reactive autoantibodies to tyrosinase and tyrosinase-related protein-2 (TRP-2). Clin Exp Immunol, 1997. 109 (3): p. 495-500.

124. Kemp, E.H., et al., Autoantibodies to human melanocyte-specific protein pmel17 in the sera of vitiligo patients: a sensitive and quantitative radioimmunoassay (RIA). Clin Exp Immunol, 1998.114 (3): p. 333-8.

125. Kemp, E.H., et al., Autoantibodies to tyrosinase-related protein-1 detected in the sera of vitiligo patients using a quantitative radiobinding assay. Br J Dermatol, 1998. 139 (5): p. 798-805.

126. Ruiz-Argüelles, A., et al., Treatment of vitiligo with a chimeric monoclonal antibody to CD20: a pilot study. Clin Exp Immunol, 2013.174 (2): p. 229-36.

127. Mandry, R.C., et al., Organ-specific autoantibodies in vitiligo patients and their relatives. Int J Dermatol, 1996. 35 (1): p. 18-21.

128. Kemp, E.H., et al., The melanin-concentrating hormone receptor 1, a novel target of autoantibody responses in vitiligo. J Clin Invest, 2002.109 (7): p. 923-30.

129. Waterman, E.A., et al., Autoantigens in vitiligo identified by the serological selection of a phage-displayed melanocyte cDNA expression library. J Invest Dermatol, 2010. 130 (1): p. 230-40.

130. Faraj, S., et al., An investigation of lamin A autoantibodies in vitiligo. J Invest Dermatol, 2017. 137 (S14).

131. Norris, D.A., et al., Evidence for immunologic mechanisms in human vitiligo: patients' sera induce damage to human melanocytes in vitro by complement-mediated damage and antibody-dependent cellular cytotoxicity. J Invest Dermatol, 1988. 90 (6): p. 783-9.

132. Gilhar, A., et al., In vivo destruction of melanocytes by the IgG fraction of serum from patients with vitiligo. J Invest Dermatol, 1995.105 (5): p. 683-6.

133. Gottumukkala, R.V., et al., Function-blocking autoantibodies to the melanin-concentrating hormone receptor in vitiligo patients. Lab Invest, 2006. 86 (8): p. 781-9.

134. Yohn, J.J., et al., Cultured human keratinocytes synthesize and secrete endothelin-1. J Invest Dermatol, 1993. 100 (1): p. 23-6.

135. Kemp, E.H., E.A. Waterman, and A.P. Weetman, Autoimmune aspects of vitiligo. Autoimmunity, 2001. 34 (1): p. 65-77.

136. Homey, B., et al., Topical FK506 suppresses cytokine and costimulatory molecule expression in epidermal and local draining lymph node cells during primary skin immune responses. J Immunol, 1998.160 (11): p. 5331-40.

137. Hartmann, A., E.B. Brocker, and H. Hamm, Occlusive treatment enhances efficacy of tacrolimus $0.1 \%$ ointment in adult patients with vitiligo: results of a placebo-controlled 12-month prospective study. Acta Derm Venereol, 2008. 88 (5): p. 474-9.

138. Gawkrodger, D.J., et al., Vitiligo: concise evidence based guidelines on diagnosis and management. Postgrad Med J, 2010.86 (1018): p. 466-71. 
139. Lee, C.-H., et al., Molecular mechanisms of UV-induced apoptosis and its effects on skin residential cells: the implication in UV-Based phototherapy. Int J Mol Sci, 2013. 14 (3): p. 6414-35.

140. Fishman, P., et al., Vitiligo autoantibodies are effective against melanoma. Cancer, 1993. 72 (8): p. $2365-9$.

141. Cario-Andre, M., et al., The melanocytorrhagic hypothesis of vitiligo tested on pigmented, stressed, reconstructed epidermis. Pigment Cell Res, 2007. 20 (5): p. 385-93.

142. Kemp, E.H., E.A. Waterman, and A.P. Weetman, Immunological pathomechanisms in vitiligo. Expert Rev Mol Med, 2001. 3 (20): p. 1-22.

143. Takechi, Y., et al., A melanosomal membrane protein is a cell surface target for melanoma therapy. Clin Cancer Res, 1996.2 (11): p. 1837-42.

144. Leonhardt, R.M., et al., Proprotein convertases process Pmel17 during secretion. J Biol Chem, 2011. 286 (11): p. 9321-37.

145. Martínez-Lostao, L., A. Anel, and J. Pardo, How do cytotoxic lymphocytes kill cancer cells? Clinical Cancer Research, 2015.21 (22): p. 5047.

146. Hassin, D., et al., Cytotoxic T lymphocyte perforin and Fas ligand working in concert even when Fas ligand lytic action is still not detectable. Immunology, 2011. 133 (2): p. 190-196.

147. Spritz, R.A. and G.H. Andersen, Genetics of vitiligo. Dermatol Clin, 2017. 35 (2): p. 245-55.

148. Bethune, M.T. and A.V. Joglekar, Personalized T cell-mediated cancer immunotherapy: progress and challenges. Curr Opin Biotechnol, 2017. 48 : p. 142-152.

149. Leisegang, M., et al., Targeting human melanoma neoantigens by $\mathrm{T}$ cell receptor gene therapy. J Clin Invest, 2016. 126 (3): p. 854-8.

150. Singh, M., et al., Cytokines: the yin and yang of vitiligo pathogenesis. Expert Rev Clin Immunol, 2019. 15 (2): p. 177-188.

151. Singh, S., U. Singh, and S.S. Pandey, Serum concentration of IL-6, IL-2, TNF- $\alpha$, and IFN $\gamma$ in vitiligo patients. Indian J Dermatol, 2012.57 (1): p. 12-14.

152. Miniati, A., et al., Stimulated human melanocytes express and release interleukin-8, which is inhibited by luteolin: relevance to early vitiligo. Clin Exp Dermatol, 2014. 39 (1): p. 54-57.

153. Gholijani, N., M.R. Yazdani, and L. Dastgheib, Predominant role of innate pro-inflammatory cytokines in vitiligo disease. Arch Dermatol Res, 2020. 312 (2): p. 123-131.

154. Moretti, S., et al., Keratinocyte dysfunction in vitiligo epidermis: cytokine microenvironment and correlation to keratinocyte apoptosis. Histol Histopathol, 2009. 24 (7): p. 849-57.

155. Boukhedouni, N., et al., Type-1 cytokines regulate MMP-9 production and E-cadherin disruption to promote melanocyte loss in vitiligo. JCI Insight, 2020. 5 (11).

156. Lengagne, R., et al., Spontaneous vitiligo in an animal model for human melanoma: role of tumorspecific CD8+ T cells. Cancer Res, 2004.64 (4): p. 1496-501.

157. Garbelli, S., et al., Melanocyte-specific, cytotoxic T cell responses in vitiligo: the effective variant of melanoma immunity? Pigment Cell Res, 2005. 18 (4): p. 234-42.

158. Fishman, P., et al., Autoantibodies to tyrosinase: the bridge between melanoma and vitiligo. Cancer, 1997. 79 (8): p. 1461-4.

159. Huang, S.K., et al., Antibody responses to melanoma/melanocyte autoantigens in melanoma patients. J Invest Dermatol, 1998.111 (4): p. 662-7. 
160. Kirkin, A.F., K. Dzhandzhugazyan, and J. Zeuthen, Melanoma-associated antigens recognized by cytotoxic T lymphocytes. Apmis, 1998. 106 (7): p. 665-79.

161. Edwards, J., et al., CD103 + tumor-resident CD8 + T cells are associated with improved survival in immunotherapy-naïve melanoma patients and expand significantly during anti-PD-1 treatment. Clinical Cancer Research, 2018. 24 (13): p. 3036.

162. Teulings, H.-E., et al., Vitiligo-like depigmentation in patients with stage III-IV melanoma receiving immunotherapy and its association with survival: a systematic review and meta-analysis. Journal of Clinical Oncology, 2015. 33 (7): p. 773-781.

163. Yee, C., et al., Melanocyte destruction after antigen-specific immunotherapy of melanoma: direct evidence of T cell-mediated vitiligo. The Journal of experimental medicine, 2000.192 (11): p. 1637-1644.

164. Tatli, A.M., et al., Association of vitiligo and response in patients with metastatic malignant melanoma on temozolomide. Tumori, 2015. 101 (2): p. e67-9.

165. Alkhateeb, A., et al., Epidemiology of vitiligo and associated autoimmune diseases in Caucasian probands and their families. Pigment Cell Res, 2003. 16 (3): p. 208-14.

166. Picardo, M., et al., Vitiligo. Nat Rev Dis Primers, 2015.1 : p. 15011.

167. Lerner, A.B., Vitiligo. J Invest Dermatol, 1959. 32 (2, Part 2): p. 285-310.

168. Jin, Y., et al., Genome-wide association analyses identify 13 new susceptibility loci for generalized vitiligo. Nat Genet, 2012.44 (6): p. 676-80.

169. Tang, X.F., et al., Association analyses identify three susceptibility Loci for vitiligo in the Chinese Han population. J Invest Dermatol, 2013. 133 (2): p. 403-10.

170. Liu, J.B., et al., Association of vitiligo with HLA-A2: a meta-analysis. J Eur Acad Dermatol Venereol, 2007. 21 (2): p. 205-13.

171. Jin, Y., et al., Variant of TYR and autoimmunity susceptibility loci in generalized vitiligo. N Engl J Med, 2010. 362 (18): p. 1686-97.

172. Jin, Y., et al., Major association of vitiligo with HLA-A* 02: 01 in Japanese. Pigment Cell Melanoma Res, 2015. 28 (3): p. 360-62.

173. Fain, P.R., et al., HLA class II haplotype DRB1*04-DQB1*0301 contributes to risk of familial generalized vitiligo and early disease onset. Pigment Cell Res, 2006. 19 (1): p. 51-7.

174. Quan, C., et al., Genome-wide association study for vitiligo identifies susceptibility loci at 6q27 and the MHC. Nat Genet, 2010.42 (7): p. 614-8.

175. Tazi-Ahnini, R., et al., The autoimmune regulator gene (AIRE) is strongly associated with vitiligo. $\mathrm{Br}$ J Dermatol, 2008. 159 (3): p. 591-6.

176. Oftedal, B.E., et al., Dominant mutations in the autoimmune regulator AIRE are associated with common organ-specific autoimmune diseases. Immunity, 2015. 42 (6): p. 1185-96.

177. Kemp, E.H., et al., Analysis of a microsatellite polymorphism of the cytotoxic T-lymphocyte antigen-4 gene in patients with vitiligo. Br J Dermatol, 1999. 140 (1): p. 73-8.

178. Birlea, S.A., et al., CTLA4 and generalized vitiligo: two genetic association studies and a meta-analysis of published data. Pigment Cell Melanoma Res, 2009. 22 (2): p. 230-4.

179. Pehlivan, S., et al., Association between IL4 (-590), ACE (I)/(D), CCR5 (Delta32), CTLA4 (+49) and IL1-RN (VNTR in intron 2) gene polymorphisms and vitiligo. Eur J Dermatol, 2009. 19 (2): p. 126-8. 
180. Li, M., et al., Functional polymorphisms of the FAS gene associated with risk of vitiligo in Chinese populations: a case-control analysis. J Invest Dermatol, 2008. 128 (12): p. 2820-4.

181. Jin, Y., et al., Common variants in FOXP1 are associated with generalized vitiligo. Nat Genet, 2010. $42(7)$ : p. $576-8$.

182. Birlea, S.A., et al., Comprehensive association analysis of candidate genes for generalized vitiligo supports XBP1, FOXP3, and TSLP. J Invest Dermatol, 2011. 131 (2): p. 371-81.

183. Ferrara, T.M., et al., Risk of generalized vitiligo is associated with the common 55R-94A-247H variant haplotype of GZMB (encoding granzyme B). J Invest Dermatol, 2013. 133 (6): p. 1677-9.

184. Jin, Y., et al., Genetic variations in NALP1 are associated with generalized vitiligo in a Romanian population. J Invest Dermatol, 2007.127 (11): p. 2558-62.

185. Jin, Y., et al., NALP1 in vitiligo-associated multiple autoimmune disease. N Engl J Med, 2007. 356 (12): p. 1216-25.

186. Alkhateeb, A. and F. Qarqaz, Genetic association of NALP1 with generalized vitiligo in Jordanian Arabs. Arch Dermatol Res, 2010.302 (8): p. 631-4.

187. Canton, I., et al., A single-nucleotide polymorphism in the gene encoding lymphoid protein tyrosine phosphatase (PTPN22) confers susceptibility to generalised vitiligo. Genes Immun, 2005.6 (7): p. 584-7.

188. LaBerge, G.S., et al., PTPN22 is genetically associated with risk of generalized vitiligo, but CTLA4 is not. J Invest Dermatol, 2008.128 (7): p. 1757-62.

189. Laberge, G.S., et al., The PTPN22-1858C $>$ T (R620W) functional polymorphism is associated with generalized vitiligo in the Romanian population. Pigment Cell Melanoma Res, 2008. 21 (2): p. 206-8.

190. Laddha, N.C., et al., Association of PTPN22 1858C/T polymorphism with vitiligo susceptibility in Gujarat population. J Dermatol Sci, 2008. 49 (3): p. 260-2.

191. Song, G.G., J.H. Kim, and Y.H. Lee, The CTLA-4 +49 A/G, CT60 A/G and PTPN22 1858 C/T polymorphisms and susceptibility to vitiligo: a meta-analysis. Mol Biol Rep, 2013. 40 (4): p. 2985-93.

192. Garcia-Melendez, M.E., et al., Protein tyrosine phosphatase PTPN22 $+1858 \mathrm{C} / \mathrm{T}$ polymorphism is associated with active vitiligo. Exp Ther Med, 2014. 8 (5): p. 1433-37.

193. Ren, Y., et al., Genetic variation of promoter sequence modulates XBP1 expression and genetic risk for vitiligo. PLoS Genet, 2009.5 (6): p. e1000523.

194. Na, G.Y., et al., Polymorphisms in the melanocortin-1 receptor (MC1R) and agouti signaling protein (ASIP) genes in Korean vitiligo patients. Pigment Cell Res, 2003. 16 (4): p. 383-7.

195. Alkhateeb, A., P.R. Fain, and R.A. Spritz, Candidate functional promoter variant in the FOXD3 melanoblast developmental regulator gene in autosomal dominant vitiligo. J Gen Intern Med, 2005. 20 (5): p. 388-91.

196. Jin, Y., et al., Next-generation DNA re-sequencing identifies common variants of TYR and HLA-A that modulate the risk of generalized vitiligo via antigen presentation. J Invest Dermatol, 2012.132 (6): p. $1730-3$.

197. Sun, Y., et al., A comprehensive association analysis confirms ZMIZ1 to be a susceptibility gene for vitiligo in Chinese population. J Med Genet, 2014. 51 (5): p. 345-53.

198. Jin, S.Y., et al., Association of angiotensin converting enzyme gene I/D polymorphism of vitiligo in Korean population. Pigment Cell Res, 2004. 17 (1): p. 84-6.

199. Wood, J.M., et al., Computer simulation of heterogeneous single nucleotide polymorphisms in the catalase gene indicates structural changes in the enzyme active site, NADPH-binding and tetramerization 
domains: a genetic predisposition for an altered catalase in patients with vitiligo? Exp Dermatol, 2008. 17 (4): p. 366-71.

200. Liu, L., et al., Promoter variant in the catalase gene is associated with vitiligo in Chinese people. J Invest Dermatol, 2010.130 (11): p. 2647-53.

201. Mansuri, M.S., et al., The catalase gene promoter and 5'-untranslated region variants lead to altered gene expression and enzyme activity in vitiligo. Br J Dermatol, 2017. 177 (6): p. 1590-1600.

202. Kim, H.J., et al., The association between endothelin-1 gene polymorphisms and susceptibility to vitiligo in a Korean population. Exp Dermatol, 2007. 16 (7): p. 561-6.

203. Gokhale, B.B. and L.N. Mehta, Histopathology of vitiliginous skin. Int J Dermatol, 1983. 22 (8): p. 477-80.

204. Nordlands, J.J., Vitiligo, in In: Pathogenesis of skin diseases, B.H.a.D. Thiers, R. L., Editor. 1986, Churchill Livingstone: New York. p. 99-128.

205. Al'Abadie, M.S., et al., Morphologic observations on the dermal nerves in vitiligo: an ultrastructural study. Int J Dermatol, 1995.34 (12): p. 837-40.

206. Al'Abadie, M., et al., Neuropeptide and neuronal marker studies in vitiligo. Br J Dermatol, 1994. 131 (2): p. $160-65$.

207. Dimitrijević, M. and S. Stanojević, The intriguing mission of neuropeptide $\mathrm{Y}$ in the immune system. Amino Acids, 2013. 45 (1): p. 41-53.

208. Ganea, D., K.M. Hooper, and W. Kong, The neuropeptide vasoactive intestinal peptide: direct effects on immune cells and involvement in inflammatory and autoimmune diseases. Acta Physiol (Oxf), 2015.213 (2): p. $442-52$.

209. Taams, L.S., Neuroimmune interactions: how the nervous and immune systems influence each other. Clin Exp Immunol, 2019. 197 (3): p. 276-277.

210. Kundu, R.V., et al., The convergence theory for vitiligo: a reappraisal. Exp Dermatol, 2019. 28 (6): p. $647-655$.

211. Cucchi, M.L., et al., Higher plasma catecholamine and metabolite levels in the early phase of nonsegmental vitiligo. Pigment Cell Res, 2000. 13 (1): p. 28-32.

212. Gauthier, Y., et al., Melanocyte detachment after skin friction in non lesional skin of patients with generalized vitiligo. Br J Dermatol, 2003. 148 (1): p. 95-101.

213. Pichler, R., et al., Vitiligo patients present lower plasma levels of alpha-melanotropin immunoreactivities. Neuropeptides, 2006.40 (3): p. 177-83.

214. Harris, J.E., Chemical-induced vitiligo. Dermatol Clin, 2017.35 (2): p. 151-161.

215. Westerhof, W. and M. d'Ischia, Vitiligo puzzle: the pieces fall in place. Pigment Cell Res, 2007. 20 (5): p. $345-59$.

216. Namazi, M.R., Neurogenic dysregulation, oxidative stress, autoimmunity, and melanocytorrhagy in vitiligo: can they be interconnected? Pigment Cell Res, 2007. 20 (5): p. 360-3.

\section{Hosted file}

2104 vitiligo review Faraj Kemp Gawkrodger.pdf available at https://authorea.com/users/ 406855/articles/517361-patho-immunological-mechanisms-of-vitiligo-an-integration-of-theimmunogenetic-milieu-with-innate-and-adaptive-immunities-as-triggered-by-environmentalstress-factors 


\section{Hosted file}

2104 vitiligo review Faraj Kemp Gawkrodger .pdf available at https://authorea.com/users/ 406855/articles/517361-patho-immunological-mechanisms-of-vitiligo-an-integration-of-theimmunogenetic-milieu-with-innate-and-adaptive-immunities-as-triggered-by-environmentalstress-factors 